\title{
EM TORNO DA PAISAGEM: LITERATURA E GEOGRAFIA EM DIÁLOGO INTERDISCIPLINAR
}

\section{AROUND THE LANDSCAPE: LITERATURE AND GEOGRAPHY IN INTERDISCIPLINARY DIALOGUE}

\author{
Ida Alves*
}

RESUMO: desenvolve-se reflexão sobre a relação literatura e paisagem, a partir de fundamentação teórico-crítica que aborda a paisagem como construção cultural capaz de expressar de maneira questionadora a relação entre sujeito, mundo e palavra. A presença da paisagem em alguma produção poética de língua portuguesa pós70 do século XX e a configuração de uma geografia lírica literária produzida por subjetividades em tensão.

PALAVRAS-CHAVE: Poesia contemporânea. Paisagem. Geografia Literária.

ABSTRACT: it is developed a reflection about the relation between literature and landscape, from a theoric-critic fundamentation that deals with the landscape as cultural building able to express in a questioning manner the relation between subject, world and word. The presence of landscape in some poetic production of the Portuguese language after the 1970s and the configuration of a urban lyrical literary geography from stressed subjectivites.

KEYWORDS: Contemporary poetry. Landscape. Literary geography.

Universidade Federal Fluminense - UFF /CNPq, Professora do Instituto de Letras, Graduação e Pós-Graduação. Coordenadora do Núcleo de Estudos de Literatura Portuguesa e Africana - NEPA UFF. Pós-Doutorado pela Université Sorbonne Nouvelle - Paris III, apoio CAPES. E-mail: idafalves@gmail.com 



\section{EM TORNO DA PAISAGEM: LITERATURA E GEOGRAFIA EM DIÁLOGO INTERDISCIPLINAR}

\section{UM TRAJETO INESPERADO}

Ao propor ${ }^{1}$ como tema a relação entre literatura e geografia a partir da noção de paisagem, desejamos pensar um trajeto interdisciplinar inesperado capaz de colaborar para uma abordagem produtiva e diversa desse objeto complexo que é o texto literário. No âmbito de nosso trabalho específico com a poesia contemporânea de língua portuguesa, venho discutindo criticamente a relação entre poesia e paisagem para compreender, com outra abordagem teórico-metodológica, a relação entre natureza e cultura, visualidade e figurações da subjetividade / alteridade, a partir de experiências de paisagem que o texto poético dá a ver e a pensar. Para tal, aliam-se a estudos contemporâneos sobre a teoria do lirismo (RABATÉ et al., 1996; COLLOT, 1997; ASEGUINOLAZA, 1999) o pensamento filosófico vindo da fenomenologia hermenêutica (sobretudo os trabalhos de Paul Ricoeur

1 Não é a primeira vez que abordo esse trajeto de pesquisa. Trato neste artigo de algumas questões sobre a relação paisagem e poesia já consideradas em trabalhos apresentados em congressos e colóquios no Brasil, Portugal e França, como reflexo do trabalho desenvolvido pelo Grupo de Pesquisa Estudos de Paisagem nas Literaturas de Língua Portuguesa, que lidero com a Profa. Dra. Marcia Manir Feitosa (UFMA). Ver http://www.gtestudosdepaisagem.uff.br 
e Merleau-Ponty) e a perspectiva crítica da geografia humanista e cultural, que, desde os anos setenta do século XX, vem produzindo inúmeros estudos sobre a experiência do espaço, a percepção da paisagem e a intervenção do simbólico nos limites da grafia da terra, dos espaços. Na área de Letras, nas últimas décadas, tem aumentado significativamente o número de estudos teórico-críticos sobre a linguagem poética como experiência radical de visualidade por meio da qual se confrontam subjetividade e alteridade, refletidas no desejo de apreender o mundo circundante pelo olhar de sujeitos fortemente urbanos. A paisagem, assim, torna-se um dispositivo muito provocador desse trajeto que liga sujeito, palavra e mundo por meio do olhar.

Por outro lado, a discussão sobre as diversas mudanças do meio ambiente como consequência da industrialização dominante e da exploração selvagem dos recursos naturais, tem se afirmado como pauta atualíssima para todos que se preocupam com a sobrevivência de nosso mundo e sua habitação sustentável. Com essa perspectiva, o discurso ecológico firmou-se e vem penetrando em diferentes áreas de pensamento em busca de novos paradigmas de existência que possam deter a destruição da vida natural e humana. Diante dessas preocupações que são cada vez mais prementes, a paisagem tornou-se uma questão de debate importante, o que se vê, por exemplo, em diferentes estudos de geografia humanista e cultural desenvolvidos em diversos centros nacionais e internacionais de investigação. Lembro, como um primeiro exemplo, o geógrafo francês Augustin Berque, cujo trabalho, "Paisagem-marca, paisagem-matriz: elementos da problemática para uma geografia cultural” (1984, tradução brasileira 2004), renovou os estudos de sua área. Mas desde 1970, o conceito de paisagem vem sendo retomado, com diferentes níveis de análise: morfológica, funcional e simbólica, para além da geografia, em diversas áreas de reflexão como (e cito apenas quatro) a estética, a psicologia, a história e a filosofia. Frente a essas demandas, a paisagem retorna não como um pré-dado, espaço inerte pré-existente e indiferente, mas como um dado construído, envolvendo percepção, concepção e ação. Contitui-se assim como uma estrutura de sentidos, uma formulação cultural, de acordo com as formulações de diferentes pensadores, nomes clássicos em seus domínios de atuação: os historiadores Alain Corbin 
(1989) e Simon Schama (1995), o professor de estética Alain Roger (1997) e o crítico de arte John Berger (2000).

Já o nosso poeta maior Carlos Drummond de Andrade mostrara como a subjetividade constrói paisagens, recolhendo memórias, experiências a partir de exercícios do olhar sobre o mundo que lhe é exterior. Esse olhar reconfigura o mundo, projeta-o para o futuro, "A paisagem vai ser.", tornando a paisagem um pensamento, uma experiência de metamorfose do sujeito. Disso é exemplar o poema "Paisagem: como se faz":

Esta paisagem? Não existe. Existe espaço

Vacante, a semear

De paisagem retrospectiva.

A presença da serra, das imbaúbas,

Das fontes, que presença?

Tudo é mais tarde.

Vinte anos depois, como nos dramas.

Por enquanto o ver não vê; o ver recolhe fibrilhas de caminho, de horizonte, e nem percebe que as recolhe para um dia tecer tapeçarias que são fotografias de impercebida terra visitada.

A paisagem vai ser. Agora é um branco a tingir-se de verde, marrom, cinza, mas a cor não se prende a superfícies, não modela. A pedra só é pedra no amadurecer longínquo.

E a água deste riacho não molha o corpo nu: molha mais tarde.

A água é um projeto de viver. 
Abrir porteira. Range. Indiferente.

Uma vaca-silêncio. Nem a olho.

Um dia este silêncio-vaca, este ranger

baterão em mim, perfeitos,

existentes de frente,

de costas, de perfil,

tangibilíssimos. Alguém pergunta ao lado:

O que há com você?

E não há nada

senão o som-porteira, a vaca silenciosa.

Paisagem, país

feito de pensamento da paisagem,

na criativa distância espacitempo,

à margem de gravuras, documentos,

quando as coisas existem com violência

mais do que existimos: nos povoam

e nos olham, nos fixam. Contemplados,

submissos, delas somos pasto,

somos a paisagem da paisagem.

(ANDRADE, 1992: 392)

É certo que a paisagem, como tema literário, foi central na compreensão do Romantismo, apresentando-se como suporte para estados da alma e para a defesa de determinados valores identitários de uma nação, que via em sua natureza a diferença necessária em relação a outros valores culturais, como foi o caso na literatura brasileira oitocentista. Os estudos que historicizam a temática da paisagem na literatura mostram a sua forte presença ao longo dos séculos XIX e XX, como também indicam a crise que pôs em debate certos elementos relacionados: a perspectiva, a representação, a figuração e a subjetividade. Após as vanguardas da primeira metade do século passado que teriam declarado de forma enfática a recusa da paisagem como figuração de mundo, a paisagem retornou como tema e fundamentalmente como estrutura significativa. Seguindo abordagem teórico-crítica de Michel 
Collot2, um dos mais ativos pesquisadores contemporâneos sobre poética e filosofia da paisagem, os processos de retomada e discussão podem ser nomeados como transfiguração, desfigurações, abstrações e refigurações, modos como a arte moderna e contemporânea trata da paisagem em busca de nomear diferentes efeitos de percepção e entendimento da relação que une homem e natureza.

Em uma de suas mais importantes obras, La poésie moderne et la structure d'horizon (1989), Collot retomou uma noção fundamental da filosofia fenomenológica de Husserl, a "estrutura do horizonte" como elemento chave de uma teorização da paisagem. Para Husserl, o horizonte faz parte da estrutura da experiência, regendo a percepção temporal e a relação subjetiva. Há um horizonte interno (os objetos contém um infinito) e um externo (os objetos estão em relação com um "campo", constituindo-se o mundo como horizonte último). Na leitura de outro filósofo, Merleau-Ponty, prin-

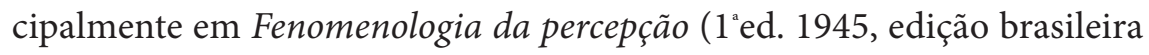
de 2006) e nas obras póstumas $O$ visível e o invisível e O Olho e o Espírito (ambas $1^{\text {a }}$ ed. 1964), desenvolvem-se criticamente as ideias de experiência de mundo e percepção, ultrapassando certos problemas que a filosofia de Husserl deixara. De fato, a noção ou categoria de horizonte será reavaliada e reaproveitada por outros pensadores, ora como um conceito, ora como metáfora, em diferentes formulações reflexivas sobre subjetividade e consciência de existência no mundo.

Ciente de um certo ostracismo por que passou a fenomenologia em França, principalmente com o desenvolvimento da crítica estruturalista, Collot preocupa-se em evidenciar que não se trata de simples retomada da experiência fenomenológica pura, e sim buscar nesse espaço conceitual a categoria e, a partir de um trabalho crítico interdisciplinar que articula fases diferentes da fenomenologia, psicanálise e linguística, construir uma abordagem teórica cujo núcleo imagístico e conceitual é o horizonte e a estrutura de horizonte, transferindo-o para a abordagem do poema e sua organização interna e externa. Examinando com atenção diferentes abordagens filosóficas, desloca-se

2 Professor de literatura francesa na Universidade Paris III, fundou e dirigiu até 2012 a Associação Horizont Paysage. Desde 2011, dirige o seminário permanente Vers une géographie littéraire. Ver http://geographielitteraire.hypotheses.org/ 
da experiência fenomenológica para a experiência ontológica, com a instituição do jogo de presença e ausência do sujeito, do mundo e do texto. Esse relacionamento entre poesia e filosofia significa a revisão da temporalidade e do espaço, agora sob a perspectiva do horizonte, isto é, o tempo presente se abre aos horizontes do tempo passado ou futuro, e o sujeito tem como o último dos horizontes a morte. A noção de distância une tempo e espaço e toda uma série de relações se estabelecem em torno do sujeito e a partir dele, expandindo-se na experiência existencial e poética, configuradas em paisagens que se apresentam à consciência, pela memória ou pelo desejo.

Do ponto de vista psicanalítico, o horizonte figura a outridade, abertura do ser ao mundo, em direção ao invisível e ao infinito, buscando figurar o infigurável: ausência / presença, proximidade / distância, trajetos da intersubjetividade. O outro é o objeto de desejo. "O outro representa originalmente para o sujeito um horizonte perfeitamente englobante, no qual ele se encontra incluso. O corpo maternal é, para o lactante o primeiro horizonte, ele se confunde com a própria "carne" do mundo." ${ }^{3}$ Da mesma forma, o horizonte como estrutura espacial transporta-se do sujeito para o texto e este passa a ser a outridade que se experimenta na sua presença / ausência, motivando o desejo de preencher o vazio que separa a palavra da coisa. Nesse sentido, o branco da folha de papel é esse espaço de vazio que se perspectiva no fundo da paisagem, ou, em direção positiva, incentiva o poeta à criação poética. A proposta de Collot nessa obra era: "Nós nos propomos a mostrar que a linguagem poética tem sempre por horizonte uma certa experiência de mundo, que, entretanto, não se dá aí senão "no horizonte", de maneira distanciada, indireta e paradoxal, porque o poema, se ele procura designar as coisas, tende também a se constituir ele próprio como um objeto puramente verbal. ${ }^{4 "}$

3 L'Autre représente à l'origine pour le sujet un horizon parfaitemente englobant, dans lequel il se trouve inclus. Le corps maternel est, pour le nourrison le premier horizon, il se confond avec la chair même du monde. (COLLOT, 1989: 99). A partir desta citação, todas as traduções em português são de minha responsabilidade.

4 Nous nous proposons de montrer que le langage poétique a toujours pour horizon une certaine expérience du monde, que pourtant ne s'y donee précisément, que 'en horizon', de manière détournée, indirecte et paradoxale, car le poème, s’il cherche à désigner les choses, tend aussi à se constituer lui-même comme un objet purement verbal. (id., p.153) 
Mais adiante afirmará que "palavras e coisas são os dois horizontes do poema”' Na linguagem poética o eu que fala é um outro, estabelecendo-se um espaço aberto que pode ser ocupado por qualquer um, para vivenciar a experiência poética que se define por três momentos essenciais: o apelo, a espera e a errância, os quais não se organizam necessariamente de forma linear no poema. O apelo é a necessidade que o poema tem de responder ao vazio e ao invisível das coisas. Existe, portanto, um apelo do horizonte desejando manifestar-se na linguagem poética. A espera, "para o poeta, é colocar-se à escuta do silêncio para perceber o eco imperceptível de um

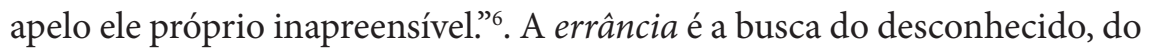
intervalo que há entre a palavra e o sujeito. "A experiência poética é assim, como a própria existência, uma totalização sempre inacabada."”

Essas formulações, aqui bastante simplificadas, acabam por levar à discussão sobre referencialidade em poesia. E Collot , leitor de Ricoeur, afirma que:

A noção de referência está frequentemente ligada aos conceitos de identidade e de objetividade. A referência é em geral concebida como o movimento por meio do qual uma palavra se identifica a um objeto definido de uma vez por todas, permitindo identificá-lo. Ora a referência poética não é nem identificante nem objetificante, mas modificante e "mundificante".

Assim, o referente do poema é um "universo imaginário" que constitui uma versão singular de mundo, já que dependente de cada subjetividade, concluindo que: "É a objetividade que é uma ficção; e o imaginário é ao

5 Mots et choses sont les deux horizons du poème [...]( id., p.153)

6 "pour le poète, c'est se mettre à l'écoute du silence pour percevoir l'écho imperceptible d'un appel lui-même insaisissable, tendu vers une réponse encore sans répondant." (COLLOT, 1989: 162)

7 "L'expérience poétique est donc, comme l'existence elle-même, une totalization toujours inachevée." (id., p.169)

8 La notion de référence est trop souvent liée aux concepts d'identité et d’objectivité. La référence est en général conçue comme le mouvement par lequel un mot s’identifie à un objet défini une fois pour toutes en permettant de l'identifier. Or la référence poétique n'est ni identifiante ni objectivante, mais modificante et mondifiante."(id., p.174). 
contrário um instrumento de conhecimento do real."9 $\mathrm{O}$ poema tece as infinitas variações de mundo, redefinindo o referente que é concebido como se fosse um reservatório contendo a totalidade das experiências que temos do objeto. Portanto, o poema não é um objeto hermético, mas se constitui como experiência de alteridade exatamente pela abertura ao além de si . "A textualidade do poema reenvia à textura do universo", já que "o poema faz ver o mundo na medida em que é ele próprio um mundo que se faz ver." ${ }^{10}$ Por outro lado, essa abertura ao mundo indica também a distância que há entre o poema e o real, entre as palavras e as coisas, porque a linguagem poética é uma tensão permanente entre o desejo de uma proximidade absoluta e a sua impossibilidade.

Em síntese, Collot considera que a noção de estrutura de horizonte permite compreender que a escrita poética é constituída pela união de dois movimentos: a constituição de uma estrutura e a abertura de um horizonte, a se refletir nos níveis da referência e organização semântica, e também nos níveis de percepção e interpretação. Assim, o ato de escrita poética encontra seu duplo no ato de sua leitura, uma vez que, como atividade hermenêutica, requer também dois movimentos: um ato de imaginação e um ato de estruturação. Com essa perspectiva, o ensaísta está claramente em diálogo com a estética da recepção, que introduziu a noção de horizonte na linguagem da teoria literária.

Ora, dessa obra fundamental da década de oitenta às suas atuais preocupações em torno da paisagem, o ensaísta tem procurado discutir a necessidade de constituir de forma mais sistemática e dialogante uma "geografia literária”, ou formular uma história da paisagem na literatura ${ }^{11}$. Também vem constituindo uma abordagem que transforma a paisagem numa fonte permanente de reflexão sobre a relação entre humanismo e habitação do mundo. Em obra publicada em 2011, La pensée-paysage, Collot demonstra com acuidade como esse pensamento se organiza e como o texto poético é seu espaço privilegiado de observação. Busca também, em seus cursos e

9 C'est l'objectivité qui est une fiction; et l'imaginaire est en revanche un instrument de connaissance du réel. (id., p.175)

10 "La textualité du poème renvoie à la texture de l'univers [...] le poème fait voir le monde parce qu'il est lui-même un monde qui se fait voir." (id., p.178)

${ }^{11}$ Ver a respeito sua obra Le payysage et poésie du romantisme à nos jours, 2005. 
seminário de pesquisa, discutir trajetos dessa "geografia literária" maior que seguem atualmente três principais orientações: 1- a geografia da literatura como interesse por lugares apresentados por escritores e sua interpretação, portanto uma abordagem crítica mais perto do referente; 2- a geocrítica como um tratamento analítico do texto literário na medida em que se observa a figuração e a construção de espaços na obra de arte, ou seja, preocupando-se com uma semiose, o significado e 3- a geopoética como uma teorização do trabalho literário, a defesa de uma poética enquanto pensamento transformador do homem. Trata-se, então, de uma ação sobre o significante, uma poeisis.

Não se objetiva, porém, no caso do estudo da poesia, impor esquemas e estruturas explicativas de outras áreas de saber, mas da problematização contínua da paisagem como um processo cultural, como efeito de um modo de ver, fixar ou movimentar identidades e subjetividades, na tensão contínua entre dentro e fora, ipseidade e alteridade, visível e invisível. Em nossa atualidade, quando predominam as noções de fragmentação, quebra, desordem, multiplicidade, os estudos de paisagem cruzam produtivamente reflexões oriundas de diferentes disciplinas que permitem a problematização da relação sujeito e mundo, revelando experiências diversas que contrapõem singularidades culturais num tempo de massificação e indiferenciação identitárias. Hoje, a relação literatura e geografia ganha outra perspectiva, na medida em que pensamos em "grafias do mundo", em modos de dizer a habitação e a integração do homem na natureza por meio da palavra imaginante.

Com essa perspectiva, no âmbito acadêmico em que muitos de nós transitamos, estou a estudar a poesia contemporânea de língua portuguesa para compreender modos e processos de fixação do olhar sobre a natureza ou sobre sua ausência. Trata-se, assim, de discutir a poesia contemporânea não como uma textualidade hermética, mas uma prática hermenêutica sobre o estar no mundo e na linguagem, por isso a ênfase na compreensão do ato poético como ato de interação entre escrita e leitura, referência e metáfora, obra e existência. Ou seja, compreender também o lirismo em sua dimensão social, histórica e política, sem deixar de ser também uma prática de linguagem e de construção textual. 
Portanto, é como uma questão contemporânea importante em torno da relação cultural e estética entre homem e natureza, por mediação do olhar, que os estudos de paisagem se encontram com os literários. Como afirmou Berque, a paisagem é uma "marca e uma matriz cultural", na medida em que é uma construção da subjetividade, um produto de cultura resultante de uma perspectiva do olhar, ou, como defenderá Alain Roger (1997: 18): o resultado de um processo de "artialização", isto é, uma paisagem resulta de toda uma elaboração da arte. Interessa-me assim, do ponto de vista do texto poético, discutir a percepção da paisagem como percepção sobre habitar o mundo e habitar a escrita, com reflexão cultural, social e estética a partir de experiências de sujeitos individuais ou coletivos de caráter urbano frente à natureza em presença ou ausência, sobre novas bases conceituais e a partir de diferentes experiências de cultura.

Entre os muitos poetas contemporâneos de língua portuguesa que poderíamos nomear para a discussão da paisagem como motor gerador de sentidos, optamos por destacar, para este artigo, a escrita de um poeta português que acabou de ganhar um prêmio internacional de poesia de grande relevância e que tem uma obra já extensa e de reconhecimento da crítica portuguesa, mas ainda muito mal conhecida do leitor brasileiro de poesia. Referimos-nos a Nuno Júdice.

\section{MODOS DE VER A PAISAGEM: A POESIA DE NUNO JÚDICE}

A configuração de paisagens é recorrente na obra desse poeta que começou a publicar em 1972 e hoje é um nome forte da produção poética portuguesa contemporânea. Ainda insuficientemente conhecido dos leitores brasileiros de poesia, seu nome foi lembrado, nos jornais brasileiros de maior circulação, por ter recebido em 16 de maio de 2013 o XXII Prémio Reina Sofia de Poesia Ibero-Americana, atribuído pelo Património Nacional espanhol e pela Universidade de Salamanca, no valor de 42.100 euros. A premiação busca "reconhecer o conjunto da obra poética de um autor vivo que, pelo seu valor literário, constitua uma contribuição relevante para o património cultural partilhado pela comunidade ibero-americana..' O júri 
constituído por dezoito personalidades ibero-americanas, em seu comunicado de premiação, indicou o poeta, ensaísta e ficcionista português como autor de uma poesia "muito elaborada, de um classicismo depurado", mas, ao mesmo tempo, com um grande compromisso com a realidade, como foi noticiado nos principais veículos de comunicação portugueses, cujos termos cito acima entre aspas. Mas, não é de hoje que esse poeta me interessa, pois há mais de três décadas vem oferecendo ao seu leitor um conjunto de obra muito representativo das questões que movem a poesia do século XX e já do XXI. Uma dessas questões é exatamente a relação entre sujeito e natureza ou sujeito e mundo, constituindo uma permanente indagação sobre o fazer poético em torno da paisagem e do olhar. Ao longo de seus livros, o olhar dos sujeitos que habitam sua poesia contemplam lugares em suas interioridades ou na rua, na cidade, transformando-os em paisagens textuais, apenas vistas ou experimentadas na linguagem. O enquadramento para a ação de ver é, de forma frequente, a janela, pois é a partir desse espaço-moldura que o(s) sujeito(s) dirige $(\mathrm{m})$ sua atenção para elementos diversos, estabelecendo os limites da própria paisagem, as suas regras de perspectiva. A janela cotidiana de cada um são os olhos por meio dos quais olham o mundo exterior; para o poeta, o texto é a janela que se abre para uma outra realidade com paisagens sempre novas. "[...] Proponho-te um jogo: abrir e fechar / janelas como quem folheia um livro.", lemos em Movimento do Mundo, no poema "Proserpina" (JÚDICE, 1996: 102)

Paisagem é o que é contemplado pelo sujeito, é um conjunto de imagens que o olhar reúne e ao qual dá significado a partir de uma determinada perspectiva. É "natureza vista através de uma cultura." ${ }^{12} \mathrm{Na}$ textualidade poética de Júdice, o sujeito lírico contempla a cidade, a rua, as pessoas que passam, ou mira o céu, o horizonte, a natureza. Algumas vezes, o que vê para além de si provoca o ensimesmar e figura uma paisagem na alma, ordenando ou desordenando os sentimentos. No poema Passagem/Paisagem, lemos essa necessidade de visualizar as emoções e, por meio disso, re-ver o mundo fora do sujeito, fazer, portanto, uma passagem entre o interior e o exterior, conciliando oposições e diferenças.

\footnotetext{
${ }^{12}$ Romano, R. (dir.), op. cit., v.1, p.107.
} 
A descrição mantém uma insistência na alma que a faz inquieta, exaltada: uma paisagem serve para dar um sentido às emoções, traduzindo-as fisicamente; e aquilo que se passa dentro dela, a vida natural, sublinha por sua vez esse claro sentido e esse preciso sentimento. Assim, é num fragmento do poema que a natureza se revela e o espírito a impregna, absorvendo a luz e as formas de tudo o que se lhe torna presente: o dia e a noite, a primavera e o inverno, a água e a terra. Mas não é só nas oposições que se encontra algo da matéria sensível do cosmos; também nas imagens que unem e conciliam os opostos,

e que se identificam com um conceito de beleza, se distingue o conflito essencial da vida e a obscura energia de um movimento imóvel. $\mathrm{O}$ amor, digo, corresponde a essa paragem no curso de um rio sem imagens; e poderá falar-se de transparência, de visão pura, ou de êxtase, no breve instante que condensa todos os instantes, e na emoção sem sentido a que todos os sentidos conduzem.

(JÚDICE, 1989: 49-50)

Sem dúvida, todo poeta é, à sua maneira, um contemplador e seu ato de ver é sempre dinâmico e provocador de transformações. O poema é, assim, um olhar verbalizado e, portanto, paisagens são todos os poemas. Entretanto, na escrita de Nuno Júdice, não há apenas o resultado do olhar, e sim, o processo e a problematização desse olhar com a avaliação da paisagem que ele define. "O caso é simples $3 / 4$ se retirarmos à / frase a filosofia que a corrompe. Os olhos / é que importam para a compreensão do / que está por dentro das palavras. / Uma imagem nunca se reduz ao plano só da abstracção / poética. Entra para dentro da alma com o seu peso concreto; e a memória com- /fere- 
-lhe a espessura do tempo." (JÚDICE, 1988: 77). Cada vez mais fortemente, o sujeito lírico fala de lugares da natureza (a terra, o mar, o céu) e da cidade (as ruas, os prédios, os lugares de encontro e desencontro, as pessoas).

Nota-se, em sua poesia, os ecos pessoanos do sentir e pensar e da problemática da alteridade. A presença desse outro poeta que, em Língua Portuguesa, ensinou a multiplicidade do ser e a atenção à escrita como realidade que se basta, lembra ao poeta contemporâneo a necessidade de ocupar a paisagem do poema como horizonte último de toda a atenção, onde a vida, os seres, a realidade e o imaginário vão se encontrar no território que é cada poema. "Todos os lugares são, / afinal, lugar nenhum para quem não habita / senão a própria voz: sonho de outra margem, / cantor perdido no labirinto das pontes. / Perto da foz, sem o saber; sonhando a nascente, / como se não fosse ele próprio a única fonte." (JÚDICE, 1997: 37).

A natureza é, em sua escrita, uma presença incontornável. É nela que o sujeito poético acompanha a passagem do tempo e aprende lições de transformação dos seres. O tempo está nas estações do ano e na duração do dia, mostrando morte e vida, destruição e renovação. O outono e o inverno trazem a tristeza, a morte, as sombras, enquanto o verão e a primavera falam da luz e da renovação da vida. Da mesma forma, a noite é o espaço das sombras, espaço da alma, enquanto o dia é domínio do corpo e da luz. Mas, é importante ver aí, não simplesmente esse contraste negativo / positivo tradicional, e sim a valorização do espaço natural, feito de sombras e luz, de vida e morte, como o lugar de início da consciência de existir, o lugar trabalhado pelo homem em harmonia com o tempo. Nessa perspectiva, o sujeito contempla o lavrar e o pastoreio, como atividades que produzem e acolhem a vida que se vai. A partir da terra, também, o poeta recupera, no imaginário, os mitos clássicos em torno das divindades agrárias e infernais. É o lugar perdido do mítico, da origem, onde o homem poderia se sentir pleno, se não fosse o que é hoje: predominantemente urbano, transformando a natureza em espaço também artificial. O poema Idade do Ouro parece contar isso:

Uma curva no tempo, como num caminho, desvia o homem da direcção antiga. De súbito, 
uma paisagem diferente: casas de madeira, a cobertura negra da ponte, o verde dos campo. Aí, senta-se numa pedra; não sabe onde está; nem ouve que o chamam, do fundo, para que regresse.

Ele sabe que pode avançar, se os olhos não fixarem a imagem conhecida. Imóvel, uma transformação faz com que as coisas estranhas se tornem perceptíveis e familiares. Assim, regressa ao rigor que os deuses lhe roubaram com o grito inicial.

Porém, outro homens avançam por essa paisagem, deitando abaixo os muros. Têm foices, enxadas, rostos embranquecidos pela vigília. Riem, uns; e cantam, quando a terra se abre em sulcos que sobem os montes, descem colinas, e se perdem na planície.

Um dia, talvez se encontrem.

(JÚDICE, 1996a: 9-10)

Porém também de cidades fala bastante o poeta. Em geral, elas não são nomeadas, porque, afinal, todas partilham certas características comuns. O sujeito poético, da janela, olha as ruas, as lojas, as pessoas que transitam em sua solidão; no carro, olha o engarrafamento, as estradas que cortam os campos; nos prédios, o vazio dos corredores, a ausência do contato e da comunicação. A cidade, qualquer cidade, grande ou pequena, é um lugar de 
passividade, de incomunicabilidade e de ausências, porém é nelas que está o "movimento do mundo" e a concentração de ruínas.

Desembarcou numa sala sem dourados nem cadeiras: madeiras velhas, jarras com flores de plástico, janelas de vidros partidos para a auto-estrada. Nem vento nem mar: só o ruído dos carros entrava pelas fendas para ecoar no tecto (madeiras à vista entre os restos de estuque). Depois, na rua, pendurou-se nos ferros podres

de antigas varandas. Percebia-se, por entre os arbustos que invadiam tudo, uma vista que teria sido digna de um quadro romântico. $\mathrm{O}$ vale, coberto de casas, e os montes invadidos por ferro-velho, ocultam um passado

de rebanhos e pastores. Mas talvez não se tenha ouvido aqui

a música da flauta. Com efeito, esta casa limita-se

a guardar antigos silêncios, que o uso transformou em manchas

sépia na memória. Agora, confundem-se com a cor das paredes;/

e só abrigam trocas de répteis, que apenas se adivinham,

no inverno, escondidos do universo. Mas alguém passou por aqui,

há pouco; e um monte de madeira fumega, ainda, enquanto

o sol avança a partir do nascente, onde as cores frias

da madrugada não se dissipam, nem pássaro algum saúda

o nascer do dia.

(JÚDICE, 1995: 127) 
Outro contraste comum em sua escrita é a relação entre terra e mar, embora no segundo andamento da poesia de Júdice, já não seja um par muito recorrente. Quando o mar se torna paisagem do poema é espaço da viagem, da alma e do imaginário, pois é nele que melhor se pode ver o céu e o seu limite virtual: o horizonte, fundamental nessa escrita poética. É interessante ainda observar que a presença desse elemento paisagístico recebe, em geral, um tratamento pessoano, figurando o "mar interior".

Quanto ao horizonte é, frequentemente, "ponto de fuga" de muitas paisagens que o sujeito lírico contempla. Não é apenas um traço representativo na pintura ou de pinturas sobre as quais frequentemente o poeta fala, mas uma imagem plurissignificante insistente em seus poemas. O dicionário registra que "horizonte, do gr. horízon, óntos, 'que limita' (subentende-se kyklos, 'círculo'), pelo lat. horizonte, significa linha circular que limita o campo da nossa observação visual, e na qual o céu parece encontrar-se com a superfície terrestre (considerada uma esfera perfeita) ${ }^{13}$. Na poesia de Júdice o horizonte não só é essa "linha circular que limita o campo da observação visual” do sujeito poético, como é metáfora múltipla: a) da interioridade desse sujeito, o lugar da intimidade, b) do próprio tempo $3 / 4$ a infinitude e c) do texto como limite da escrita. É também um espaço de contradição, pois tanto significa a potencialidade, a plenitude e a totalidade, como representa o vazio, a solidão e a impossibilidade. Se o espaço celestial remete para o transcendente, a espiritualidade plena, a superação da condição terrestre, também intensifica a pequenez, o isolamento e a precariedade humana na terra. Na obra de Nuno Júdice, a permanência dessas interrogações cognitivas pode significar a continuidade da rejeição da realidade urbana contemporânea, múltipla, fragmentada, caleidoscópica, artificial e desumanizadora, forçando o sujeito poético a buscar na linguagem sua resistência, um humanismo capaz doar sentidos ao mundo circundante.

Trabalha agora na importação e exportação. Importa metáforas, exporta alegorias. Podia ser um trabalhador por conta própria,

13 Cf. Ferreira, A.B.H. (1986). 
um desses que preenche cadernos de folha azul com números

de deve e haver. De facto, o que deve são palavras, e o que tem

é esse vazio de frases que lhe acontece quando se encosta

ao vidro, no inverno, e a chuva cai do outro lado. Então, pensa

que poderia importar o sol e exportar as nuvens. Poderia ser

um trabalhador do tempo. Mas, de certo modo, a sua prática confunde-se com a de um escultor do movimento. Fere,

com a pedra do instante, o que passa a caminho da eternidade;

suspende o gesto que sonha o céu; e fixa, na dureza da noite,

o bater de asas, o azul, a sábia interrupção da morte.

(JÚDICE, 1999: 136)

Um outro aspecto a pensar nessa abordagem da paisagem pelo poesia toca as figurações de uma identidade cultural. Quando um poeta descreve as paisagens que lhe importam, é comum que se destaquem as paisagens da terra natal. Então, o leitor poderá perguntar: na poesia de Júdice, poeta português, estão presentes as paisagens de seu país? A resposta nos leva a outra questão importante na obra desse escritor e se relaciona à discussão sobre identidade e nacionalismo, cosmopolitismo e provincialismo.Vejamos.

As paisagens exteriores à janela na poesia de Júdice são, como vimos, urbanas ou naturais. As urbanas podem ser de qualquer cidade contemporânea de maior porte, até mesmo Lisboa ou de pequenas cidades de qualquer país, com sua vida monótona, acomodada e distanciada da agitação e conturbação das metrópoles. Sob esse ponto de vista, existe uma indiferenciação de nacionalidade, como se o poeta precisasse se libertar do adjetivo 
"português" para se encontrar na universalidade do poético, sem pátrias ou bandeiras, num movimento de superação do local.

Nas suas obras publicadas, aproximadamente, até o ano de 2000, não é comum a nomeação explícita de espaços, de lugares de Portugal como referentes objetivos num corpus poético que é muito extenso. Alguns poemas lembram paisagens da infância, sem, no entanto, serem nomeadas diretamente. Portanto, haveria nisso uma rasura de identidade espacial? A resposta simplesmente afirmativa seria um equívoco na compreensão de sua obra, porque se as paisagens não nomeiam (ou muito pouco) Portugal, essas paisagens são produzidas por um olhar português e são estabelecidas no território da língua portuguesa. Júdice acaba por realizar a frase-mote de Pessoa / Bernardo Soares: a minha pátria é a língua portuguesa e com esse estatuto topológico na linguagem, o seu Portugal é fingido silêncio, topos deslocado em confronto tenso com o olhar europeu. É preciso imaginar-se outro para se reconhecer, para dizer a identidade plural de sua cultura. A partir de 2000, toda a produção que se segue passa a expor de forma mais evidente essa cultura portuguesa, seja por tratar diretamente de questões do mundo de língua portuguesa, seja pelas referências diretas a escritores portugueses de diferentes séculos, a sinais concretos de espaços percorridos. Veja-se especialmente a obra Cartografias de Emoções, de 2001.

A figuração de paisagens é, na matéria do poema, um jogo de textualidades, encontro de caminhos de cultura (e recorro à plurissignificação do termo...) a que a poética de Júdice dá voz e imagens, interrogando seu sentido (do poema? da paisagem? da escrita?) nesta nossa contemporaneidade. Em tempo de perda quase completa de uma existência bucólica, as experiências da natureza como paisagens configuradas ou desfiguradas pelo sujeito lírico apontam também a necessidade urgente de reencontrar um "pensamento-paisagem”, como defende Michel Collot. Em poéticas como essa, por vezes mal compreendidas como estetizantes ou excessivamente líricas, "a paisagem aparece como a própria imagem do mundo vivido” (COLLOT, 2011: 23) e a escrita de poesia torna-se, então e simultaneamente, uma forma de questionar o nosso desconcerto e um caminho de retorno, com a certeza de que o mundo à nossa volta, apesar de toda tecnologia e de toda desilusão, é ainda nossa única casa, a geografia limite de nosso olhar. 


\section{REFERÊNCIAS BIBLIOGRÁFICAS}

ASEGUINOLAZA, Fernando Cabo (compilación). Teorías sobre la lírica. Madrid: Arco/Libros, 1999.

ANDRADE, Carlos Drummond de. Poesia e prosa. Rio de Janeiro: Nova Aguilar, 1992.

BERGER, John. Modos de ver. Barcelona: Gilli, 2000.

BERQUE, Augustin. Paisagem-marca, paisagem-matriz: elementos da problemática para uma geografia cultural. In: CORREAA, Roberto Lobato e ROSENDAHL, Zeny. Paisagem, tempo e cultura. Rio de Janeiro: EdUERJ, 2004.

COLLOT, MICHEL. La poésie moderne et la structure d'horizon. Paris: PUF, 1989.

. (dir). Les enjeux du paysage. Paris: Ousia, 1997.

. La matière-émotion. Paris: PUF, 1997.

. Paysage et poésie du romantisme à nos jours. Paris: José Corti, 2005.

. La pensée-paysage. Paris: Actes SUD / ENSP, 2011.

CORBIN, Alain. O território do vazio - a praia e o imaginário ocidental. São Paulo: Cia das Letras, 1989.

JÚDICE, Nuno. A condescendência do ser. Lisboa: Quetzal, 1988.

. Enumeração de sombras. Lisboa: Quetzal, 1989.

. Um canto na espessura do tempo. Lisboa: Quetzal, 1992. 
. Meditação sobre ruínas. 2. ed. Lisboa: Quetzal, 1996a.

. O movimento do mundo. Lisboa: Quetzal, 1996.

. A fonte da vida. Lisboa: Quetzal, 1997.

. Teoria geral do sentimento. Lisboa: Quetzal, 1999.

. Cartografias de emoções. Lisboa: Quetzal, 2001.

MERLEAU-PONTY, Maurice. Fenomenologia da percepção. São Paulo: Martins Fontes, 2006.

. O visível e o invisível. São Paulo: Perspectiva, 1991.

. O olho e o espírito. In: DUARTE, Rodrigo (org. e sel.). O belo autônomo. Belo Horizonte: Editora

UFMG, 1997.

RABATÉ, Dominique et al. Le sujet lyrique en question. Bordeaux: Presses Universitaires de Bourdeaux, 1996.

ROGER, Alain. Court traité du paysage. Paris: Gallimar, 1997.

SCHAMA, Simon. Paisagem e memória. São Paulo: Cia das Letras, 1995. 